\title{
Integrating Equity and Reconciliation Work into Archival Descriptive Practice at the University of Waterloo'
}

\author{
DANIELLE ROBICHAUD
}

\begin{abstract}
Despite sustained calls for a critical review of harmful content within archival descriptive records, there remains much to be explored by way of implications for Canadian academic archives. This article addresses the absence of Canadian archival practitioners in broader discussions about the revision and remediation of descriptive records by exploring how staff in Special Collections \& Archives at the University of Waterloo Library are working to integrate equityand reconciliation-informed thinking into the department's archival practice by revising their approach to language in archival descriptions. Beginning with an overview of the department and the landscape in which it operates, this article provides a brief review of guidance available in the Rules for Archival Description. It then provides the rationale behind the recent changes to descriptive practice before exploring a series of examples of how and where this work is newly underway. The article concludes with a consideration of current identified challenges and the related work ahead.
\end{abstract}


RÉSUMÉ Malgré les appels répétés pour une revue critique du contenu blessant dans les descriptions d'archives, il reste beaucoup à explorer en termes de ce que cela signifie pour les archives universitaires canadiennes. Cet article aborde l'absence des archivistes praticiens canadiens dans les discussions générales autour de la révision et de la réhabilitation des notices descriptives en explorant comment le personnel des Collections spéciales et des Archives à la Bibliothèque de l'Université de Waterloo travaille à intégrer une pensée tenant compte de l'équité et de la réconciliation dans les pratiques archivistiques du département en revisitant leur approche au langage dans la description archivistique. Commençant par un survol du département et du décor dans lequel il opère, l'article offre un bref aperçu des directions disponibles dans les Règles pour la description des documents d'archives. Il fournit ensuite les raisons sous-jacentes aux récents changements dans les pratiques descriptives avant d'aborder une série d'exemples illustrant comment et où ce travail est en cours depuis peu. Cet article se termine en se penchant sur les défis actuels et le travail à venir pour leur répondre. 


\section{Introduction}

In April 2020, Special Collections \& Archives (SCA) at the University of Waterloo Library (UWaterloo) in Waterloo, Ontario, released a revised statement on language in archival descriptions. The changes were introduced as an intentional integration of equity- and reconciliation-informed thinking into the department's archival practice. Consisting of a series of descriptive interventions to address the perpetuation of systemic and cultural bias, they were established to support ongoing efforts by staff to identify and acknowledge known instances of discrimination that appear throughout SCA's holdings. The formalization of these interventions was directly informed by the landscape in which the department operates, including governing policies and standards in place on campus and within the profession as a whole. ${ }^{2}$ They were equally informed by sustained calls for accountability within the archival profession regarding its role in upholding homogenous historical narratives rooted in the assumed supremacy of cis-, able-bodied whiteness. ${ }^{3}$ This desire for accountability also responds to the calls put forth by the Truth and Reconciliation Commission of Canada with regard to education about and access to records related to the residential school system and the settler colonialism that informed the system's creation. ${ }^{4}$ Finally,

University of Waterloo employees are expected to follow a series of principles of inclusivity, against which performance as individuals and as campus units is reviewed annually. The principles include the promotion of inclusivity through the reasonable adjustment of procedures and all forms of communication. SCA staff have interpreted these principles as extending to archival descriptive records. University of Waterloo faculty and staff are also governed by a series of policies. The general principles of Policy 33, Ethical Behaviour, which in part reflects the Ontario Human Rights Code, require that "each member of the University endeavour to contribute to the existence of a just and supportive community based on equality and respect for individual differences." University of Waterloo, Policy 33, Ethical Behaviour (last updated: June 30, 2010), https://uwaterloo.ca /secretariat/policies-procedures-guidelines/policy-33. From a professional standpoint, the Association of Canadian Archivists' Code of Ethics and Professional Conduct underscores principles such as context, access, and integrity with regard to ethical professional conduct. SCA staff have interpreted these principles as extending to the use of accurate, precise, and direct language while (re)describing archival holdings.

Examples include Michelle Caswell, "Teaching to Dismantle White Supremacy in Archives," Library Quarterly 87, no. 3 (2017): 222-35; Jarrett M. Drake, "RadTech Meets RadArch: Towards A New Principle for Archives and Archival Description," On Archivy (blog), April 6, 2016, https://medium.com/on-archivy/radtech-meets -radarch-towards-a-new-principle-for-archives-and-archival-description-568f133e4325; Sara White, "Crippling the Archives: Negotiating Notions of Disability in Appraisal and Arrangement and Description," American Archivist 75, no. 1 (2012): 109-24; Sam Winn, "The Hubris of Neutrality in Archives," On Archivy (blog), April 24, 2017, https://medium.com/on-archivy/the-hubris-of-neutrality-in-archives-8df6b523fe9f.

4 Truth and Reconciliation Commission of Canada, Truth and Reconciliation Commission of Canada: Calls to Action (Winnipeg, MB: Truth and Reconciliation Commission of Canada, 2015), http://trc.ca/assets/pdf/Calls_to _Action_English2.pdf. Although released after the revision of SCA's statement regarding archival descriptions, 
the changes demonstrate an attempt to meaningfully put organizational and personal commitments related to equity and reconciliation into practice.

What follows is an overview of how SCA staff have begun to transition beyond making vague, blanket statements about the era in which records were produced to explore reconciliatory actions that go beyond the rote land acknowledgements now common within academic spheres. ${ }^{5}$ This article is an attempt to talk openly about the work and reflection required to push aside desires to have the right answer before implementing change(s), to get comfortable with not confidently knowing how, and to make good-faith improvements anyway. It is a means of holding myself, my colleagues, and my place of work accountable by documenting the why and how of where we find ourselves, from an equity and reconciliation standpoint, and by demonstrating how things are progressing as we attempt to shift that position over time. Finally, it is a contribution aimed at addressing an absence, in the related literature by Canadian archival practitioners, of discussions about the equity- and reconciliation-related revision and remediation of archival descriptions.

Beginning with an overview of the department and the landscape in which it operates, this article provides a brief review of guidance available in the Rules for Archival Description. It then provides the rationale behind the recent changes to descriptive practice before exploring a series of examples of how and where this work is newly underway. The article concludes with a consideration of current identified challenges and the related work ahead.

the draft of $A$ Reconciliation Framework for Canadian Archives, released in July 2020, is equally relevant as it firmly identifies the Canadian archival community's responsibility for "not only acknowledging the colonial roots of archival theory, practice and research, but taking action to redress past and continuing harms to Indigenous communities." Response to the Report of the Truth and Reconciliation Commission Taskforce of the Steering Committee on Canada's Archives, A Reconciliation Framework for Canadian Archives (draft for public review, July 2020), https://archives2026.files.wordpress.com/2020/07/reconciliationframeworkforarchives_july2020_en.pdf.

5 For more on the relationship between academic land acknowledgements and action, see Chelsea Vowel, "Beyond Territorial Acknowledgments," âpihtawikosisân (blog), September 23, 2016, https://apihtawikosisan .com/2016/09/beyond-territorial-acknowledgments/. 


\section{Department Overview}

Special Collections \& Archives opened in 1976, although its roots date back to the 1960s, when UWaterloo's first university librarian, Doris Lewis, began overseeing the collection of rare books and archival records. One of the department's foundational donations was the Lady Aberdeen Library on the History of Women, donated in 1967 as a Canadian Centennial project by the National Council of Women of Canada (NCWC). ${ }^{6}$ It was followed by donations of papers by both the NCWC and its members, which in turn attracted donations from Canadian writers, journalists, and broadcasters affiliated with the Canadian Women's Press Club. Today, the department maintains several hundred fonds and collections reflecting 15 thematic areas ${ }^{7}$ in addition to an extensive collection of rare books and periodicals. The department is unique among Canadian academic archives due to an extensive and heavily used local history collection that reflects the development of the region - holdings that are more commonly found in public, municipal, or community archives. Among these is the heavily used Kitchener-Waterloo Record Photographic Negative Collection, consisting of approximately 2 million negatives shot between the late 1930s and 2001, when the newspaper transitioned to digital photography.

The department mandate is to acquire and make available material that supports the goals of the major teaching and research programs at UWaterloo. ${ }^{8}$ In doing so, SCA is a public-facing department, meaning that staff regularly assist the public with everything from questions about local buildings or family-related research to more in-depth requests tied to film productions or retrospective events and exhibits. SCA is also responsible for maintaining and providing access to the University of Waterloo Archives (UWA), which preserves recorded information of enduring administrative, legal, financial, or historical value related to the university. ${ }^{9}$ Prior to the onset of COVID-19, the department

For more on the history of SCA's women's studies holdings, see Susan Bellingham, "Women's Studies Collections in the University of Waterloo Library," Atlantis: Critical Studies in Gender, Culture and Social Justice 10, no. 2 (1985): 147-61, accessed November 17, 2020, https://journals.msvu.ca/index.php/atlantis/article/view/4417/3657.

"Thematic Areas," University of Waterloo Archives Database, accessed October 24, 2020, https://archives .uwaterloo.ca/thematic-areas.

8 "About Special Collections \& Archives," University of Waterloo Special Collections \& Archives, accessed October 24, 2020, https://uwaterloo.ca/library/special-collections-archives/about.

"University Archives," University of Waterloo Special Collections \& Archives, accessed October 24, 2020, 
averaged 1,200 reference requests per year from on- and off-campus researchers who made contact by phone, email, and in person regarding holdings in both SCA and the UWA. ${ }^{10}$

There are currently six full-time staff members in the department: four librarians or archivists, including the head of the department, and two library associates. ${ }^{11}$ In addition to the full-time staff, SCA relies on part-time assistance from the library's cataloguing department to help with the processing of rare books and historical maps. There is also often at least one UWaterloo co-op student or an MLIS student from another university working in the department each term to assist with scanning, data entry, rehousing, and other day-to-day operations.

\section{Equity and Reconciliation in the Waterloo Landscape}

SCA's current approach to language in archival descriptions was formalized in April 2020, the result of discussions that have been underway for several years. The corresponding statement about the changes was influenced by suggestions for enacting transparency regarding descriptive interventions to address racism, which were put forth by the Archives for Black Lives in Philadelphia Anti-Racist Description Working Group. ${ }^{12}$ The formalization and public sharing of changes to SCA's archival description practice has been heavily informed by the environment in which the department operates - both inside and outside the library as well as on and off campus.

At the department level, there was a complete staff turnover in the mid-2o10s. The current team has been with the department for anywhere from three to seven years, meaning that we are well positioned to reimagine and redirect how

https://uwaterloo.ca/library/special-collections-archives/collections/university-archives.

10 At the time of writing, final reference counts for 2020 were not yet available. On-campus requests have historically outnumbered off-campus requests due to the availability of walk-in services and class-based assignments requiring students to visit the department.

11 I will return to their demographics and backgrounds later in the article.

12 Archives for Black Lives in Philadelphia's Anti-Racist Description Working Group, "Archives for Black Lives in Philadelphia Anti-Racist Description Resources" (Philadelphia, PA: Archives for Black Lives, 2019), https://archivesforblacklives.files.wordpress.com/2019/10/ardr_final.pdf. Given the absence of these types of statements in the Canadian archival landscape, the department also referred to various available examples from American academic archives. 
the department operates and what new or existing services get prioritized. One of the earliest identified priorities was to improve online access to the department's holdings and the information available about them. This decision marked an intentional shift from an operational focus predominantly aimed at accommodating in-person, private research pursuits to an active, outward-facing archival program aimed at inviting in researchers - both those using archives for the first time and seasoned experts. Shortly after I started, in a newly established digital archivist position in 2016, I was tasked with overseeing the launch of the Waterloo Digital Library (which runs on Islandora), which is used to share a selection of the department's digitized records. I am also responsible for the management and ongoing migration of descriptive records from a series of internal databases to the Archives Database (which runs on AtoM), an online descriptive platform launched in 2019 to facilitate open and evolving access to SCA's descriptive records. ${ }^{13}$

The launch of the Waterloo Digital Library and the Archives Database prompted a focused and ongoing review of legacy descriptive records. Although the review process has been slow and time intensive, the resulting (re)description work represents a high-impact net benefit since more information online means more people seeing, using, and drawing conclusions about the records SCA has to offer. That reality has resulted in a sustained consideration of how to best present information about the records in the department's care, particularly those documenting a less savoury aspect of the era in which they were produced. Initially, problematic content ${ }^{14}$ shared online was accompanied by a note indicating that the ideas expressed did not reflect UWaterloo's views, an approach SCA staff quickly realized works only until someone questions why they do not reflect the views of the school.

From a campus standpoint, it is important to note that, in the summer of 2020 , UWaterloo's Associate Vice-President for Human Rights, Equity and Inclusion, Diana Parry, resigned following sustained criticism from \#EQUITY 4 WHO,

13 For more information about the migration and how it aligns with archival descriptive changes, see Danielle Robichaud, "Migrating Archival Descriptive Records to AtoM: The Good, the Bad and the Yikes," Off the Record 36, no. 4 (2020) 14-17, http://hdl.handle.net/10012/16495.

14 Problematic content is used here and elsewhere to refer to archival records within SCA holdings that have been deemed to undermine the department and university's commitment to equity- and reconciliation-informed policies and guidelines. This includes records reflecting racist, sexist, homophobic, transphobic, fatphobic, ableist, and otherwise discriminatory or harmful imagery and viewpoints. 
a grassroots student group that openly documented the repeated shortfalls of equity and anti-racism efforts on campus with regard to the needs of Black and Indigenous students, staff, and faculty. ${ }^{15}$ Although this is a recent example, the concerns that led to the resignation have been raised and, in some cases, have been present on campus for years. In 2017, members of the Black Association for Student Expression were told by school officials that they would have to collect statistics themselves in order to prove a shortage of on-campus services for Black students, since the school did not collect data about racialized students. ${ }^{16}$ Data and equity were also at the forefront of campus happenings in 2016, when UWaterloo increased the compensation of women faculty members after an internal review determined that a "systemic gender anomaly" was resulting in inequitable pay. ${ }^{17}$

Finally, the history of the Region of Waterloo needs to be considered as it directly impacts both the collections and the operations of SCA. The region is situated on the Haldimand Tract, land that was promised to the Six Nations in 1784 in return for their support of the British during the American Revolution. It includes six miles on each side of the Grand River. ${ }^{18}$ What is today Kitchener-Waterloo was first settled by Mennonites from Pennsylvania in the early 1800 . As the region grew and developed into Ontario's industrial hub, wealthy, predominantly white industrialists followed. Although the region today is culturally diverse - partly due to the international draw of various science and technology companies and multiple universities and colleges - its German heritage has continued to be a primary focus within local history communities and features prominently in tourism experiences like Oktoberfest and St. Jacobs Farmers' Market. Unfortunately, the pride associated with the region's more

15 Fitsum Areguy, "UW Vice-President of Equity Steps Down," The Record, July 31, 2020, https://www.therecord.com /news/waterloo-region/2020/07/31/uw-vice-president-of-equity-steps-down.html; Jansher Saeed, "Students

Call Out UW on Its State of Equity," Imprint, August 3, 2020, http://uwimprint.ca/article/students-call-out-uw-on -its-state-of-equity/.

16 "Group Told They Need to Prove UW Not Doing Enough for Black Students," CBC News, November 27, 2017, https://www.cbc.ca/news/canada/kitchener-waterloo/black-association-student-expression-university -waterloo-1.4421077.

17 Sara Mojtehedzadeh, "University of Waterloo Boosts Salaries of Female Faculty," Toronto Star, August 4, 2016, https://www.thestar.com/news/canada/2016/08/04/university-of-waterloo-boosts-salaries-of-female-faculty .html.

18 "The Haldimand Treaty of 1784," Six Nations Lands and Resources, accessed November 17, 2020, http://www.sixnations.ca/LandsResources/HaldProc.htm. 
homogenous roots can be linked to persistent race-based discrimination and an inclination, particularly among white citizens, to deny that skin colour is a source of that discrimination. Recent examples include the dismissive responses to Indigenous community members' concerns about the appropriateness of the Prime Ministers Path in Baden, Ontario, following repeated vandalizations of the Sir John A. Macdonald statue; ${ }^{19}$ the racist behaviour directed toward Land Back advocates in Kitchener's Victoria Park; ${ }^{20}$ and police chief Bryan Larkin's undermining of the reliability of a data-driven report that showed that 66 percent of the people who experienced use-of-force responses from Waterloo Regional Police between January and June 2020 were Black. ${ }^{21}$

On their own, these various snapshots of the landscape in which SCA operates may not seem immediately related, but combined, they can be understood as an unignorable perfect storm. SCA is working to push forward services that improve access to and awareness about its holdings against a backdrop of important and challenging discussions about equity, race, and reconciliation. And staff are doing so as requests for primary resources related to equity-seeking groups and the rhetoric used to push them to the margins are on the rise in both personal research and instructional contexts.

Cali Doran, "Debate Continues over Future of SJAM Statue in Baden," Kitchener Today, June 29, 2020,

https://www.kitchenertoday.com/local-news/debate-continues-over-future-of-sjam-statue-in-baden-2527650; Waterloo Regional Record, "Wilmot Council Isn't Ready to Decide on Pausing Controversial Statue Project," The Record, July 14, 2020, https://www.therecord.com/news/waterloo-region/2020/07/14/wilmot-council-isnt -ready-to-decide-on-pausing-controversial-statue-project.html. Laura Booth, "Racist Graffiti Found on Spurline Trail Is 'Disgusting and also Terrifying,' Says Indigenous Activist," Waterloo Chronicle, October 4, 2020, https://www.waterloochronicle.ca/news-story/10216051-racist-graffiti -found-on-spurline-trail-is-disgusting-and-also-terrifying-says-indigenous-activist/; Joel Rubinoff, "Indigenous Land Back Camp Challenges Perceptions," The Record, August 24, 2020, https://www.therecord .com/news/waterloo-region/2020/08/24/indigenous-land-back-camp-challenges-perceptions.html.

21 Paula Duhatschek, "Initial Numbers Show Black People Over-Represented in 2020 Police Use of Force Incidents," CBC News, October 15, 2020, https://www.cbc.ca/news/canada/kitchener-waterloo/black-people-over -represented-use-of-force-wrps-2020-1.5762629; Casey Taylor, "Waterloo Region's Top Cop Says Officers Do Not Use Force More Often against Black People," Kitchener Today, October 14, 2020. https://www.kitchenertoday .com/police-beat/waterloo-regions-top-cop-says-officers-do-not-use-force-more-often-against -black-people-2792081. 


\section{Equity, Reconciliation, and the Rules for Archival Description}

The announcement about the formal changes to SCA's approach to language in archival descriptions noted that the existing archival descriptive standards lacked clear, current directions for handling problematic content. ${ }^{22}$ While that remains true, the Rules for Archival Description ( $R A D)$, the descriptive standard followed by the department, can be used to rationalize the introduction of equity- and reconciliation-informed thinking in day-to-day archival practice. For example, $R A D$ outlines three core purposes of archival description:

1. To provide access to archival material through retrievable descriptions;

2. To promote understanding of archival material by documenting its content, context and structure; and

3. To establish grounds for presuming the authenticity of archival material by documenting its chain of custody, arrangement, and circumstances of creation and use. ${ }^{23}$

$R A D$ also expands on these purposes in a manner that underscores the autonomy of the archivist to acquire and manage archival records and to make them accessible in the way that best suits the context: "The rules recognize the necessity for judgement and interpretation on the part of both the person who performs the description and the institution responsible for it. Such judgement and interpretation may be based on the requirements of a particular finding aid or upon the use of the material being described." 24

Although there are many ways to interpret descriptive standards, these particular points can be understood to emphasize the importance of describing records so that they are findable and so that the context in which they were created is clearly documented. Further, they emphasize that this should be done

\footnotetext{
22 "Language in Archival Descriptions Changes," University of Waterloo Library Special Collections \& Archives, April 27, 2020, https://uwaterloo.ca/library/special-collections-archives/news/language-archival-descriptions -changes.

23

Canadian Committee on Archival Description, Rules for Archival Description (Ottawa: Canadian Council of Archives, 2008), xxii. 
in a way that best meets the requirements of the set of records, the needs of end-users, and the environment in which they are being used. Considered from a practitioner standpoint, one can reasonably interpret $R A D$ 's direction as empowering SCA staff and holding them responsible for providing access to archival records in a manner that interacts with, speaks to, and accurately documents the moment in which they are being used.

\section{Reasons for Expanding the Statement}

Ultimately, SCA staff needed to determine how to engage with broader discussions taking place around us while, at the same time, working to better reflect the realities of the people we were mandated to serve and whose histories we had been tasked with documenting. Not to acknowledge or understand the depth of this moment would have been to fall short with regard to accurately capturing and talking about the history of the department, UWaterloo, and the region, and it would also have meant neglecting the department's mandate to support the interests of on- and off-campus researchers. Not making the changes might have also inadvertently signalled to potential researchers and donors that the department existed only to document a certain type of history and uphold a certain type of narrative around this.

To that end, in April of 2020, SCA released a revised statement regarding language in archival descriptions, which outlined areas of focus related to equity and reconciliation efforts in day-to-day practice. The changes reflect a formalization of ongoing staff efforts to acknowledge known instances of discrimination that appear in archival records. Although staff had previously relied on a general acknowledgement of problematic language in archival descriptions, this had amounted to a blanket statement about historical records reflecting the era in which they were produced. ${ }^{25}$ That approach was not necessarily bad, and it

The statement included on the Waterloo Digital Library at the time of its public launch in 2017 read,

\footnotetext{
Material made available on the WDL is historical in nature and contains language or depictions of people representative of its time. This includes wording, cultural references and stereotypes that may no longer be used or appropriate today. Historical language has been maintained in its original form, in keeping with archival practice, to preserve the context in which the associated records were created. This approach, while potentially upsetting, allows for the critical assessment and questioning of historical material by contemporary researchers.
} 
continues to be employed by many cultural organizations. What complicated the approach for me was an increasing discomfort with the "sorry if you were offended" tone that is implied in these kinds of statements - in part because it highlights a disconnect between my stated commitments to equity and reconciliation, as well as those of my place of work, and the reality of putting those beliefs into action in both my personal and professional life. I feel strongly that if individuals and organizations say that we are serious about addressing and dismantling racist and colonial structures, we need to act in ways that demonstrate, enact, and enable that desire. We also need to be very clear about why we are doing it. Thinking critically and intentionally about the language used in descriptive records is one way to follow through on those commitments.

The turning point in SCA's approach to archival descriptive work took place in 2019, while my colleague Sue Plouffe was seeking knitting-related photos to promote an event. She found what she initially thought would be a good candidate, from 1965, only to realize once the image was scanned that it included an unequivocally racist depiction of a Black man as part of a "Boys Slave Day" event at a local high school.

Even with the racist poster obscured, ${ }^{26}$ it is worth noting how seamlessly racist imagery and ideas are woven into seemingly innocuous historical records and, more to the point, our daily lives. For example, the quaint-sounding photo title - "Waterloo High School Knitting Bee" - does not hint in any way at the racism openly displayed in the poster.

The views expressed in the material shared on the WDL should be taken as a product of the era in which it was produced and in no way reflects the current opinion, goals or ethics of the Library or the University of Waterloo as a whole.

"About," University of Waterloo Digital Library, Internet Archive, December 10, 2018, accessed November 20, 2020, https://web.archive.org/web/20181210144835/https://digital.library.uwaterloo.ca/about.

The poster has been redacted because readers do not need to see it to know what kind of dehumanizing imagery it includes. We have all seen the type of harmful, racist caricature it features, and likely numerous times at that. Redacting the image was a personal decision that does not reflect how SCA would handle a request to release the image for personal use or research purposes. Blocking the release of this image in its original form would create a gatekeeping issue akin to suppressing information about the existence of these types of records. That said, there are no plans to include this set of images on the WDL as part of SCA's digitized offerings for online browsing. 


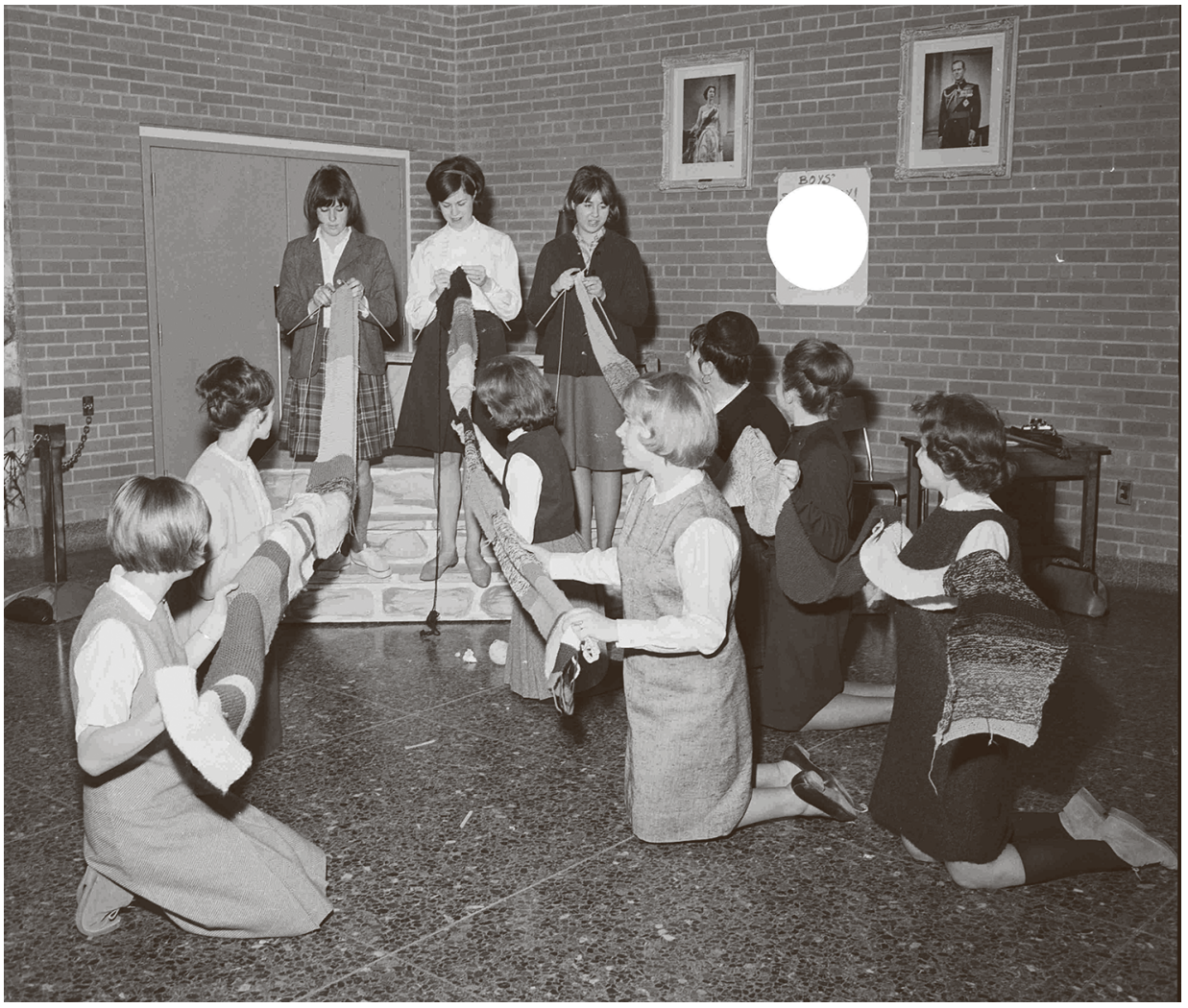

FIGURE 1 Negative from the Kitchener-Waterloo Record Photographic Negative Collection, titled "Waterloo High School Knitting Bee." Source: University of Waterloo Library, Special Collections \& Archives, Kitchener-Waterloo Record Photographic Negative Collection, 65-1330_0o4, Waterloo High School knitting bee, February 26, 1965.

Everyone working and studying at this school would have seen it and would have had an opportunity to object to the event. At the same time, while the photographer could have reframed the shot, the advertisement is visible on the wall as if racism is just obvious - a given that no one thinks, or thought, twice about. If we, as a department, had not already been discussing the impact of unacknowledged racist content in the records we publicly share, this may have gone unnoticed, not because we are okay with open displays of racism, but because the poster is relatively small and quietly woven into the rest of the shot, making it easy to miss. 
Once the racist poster was identified, an easy decision was made to exclude the image from the department's promotional effort, and this was followed by discussions about how to document and track known racist content in our descriptive records. Prior to the launch of the Archives Database, we would have added an internal note to the relevant record that only staff could see, but the description for this photo is now public, and we needed to figure out how to identify the issue. The solution we settled on was to add a content warning to the general note field that reads, "Boys' Slave Day poster with racist depiction of a Black person visible on wall behind knitting bee participants." ${ }^{27}$ Euphemisms were intentionally avoided, and racist was used to identify the issue clearly and accurately. Work on this front has since been expanded to document instances of black-, brown-, yellow- and redface, particularly in historical photographs of children and costume parties, where this form of racism is rampant.

\section{Stated Commitments in Action}

Since publicizing our decision to address problematic language and content more intentionally, SCA staff have been asked repeatedly for examples of interventions in action. Beyond identifying forms of discrimination immediately apparent in photographic material, we have established a series of descriptive guidelines for reference during the (re)description process. The work to enact them has only just begun and is being executed as descriptions are reviewed for migration across platforms, as records are described for the first time, or as problematic content is identified during instruction- or reference-related work. The still evolving guidelines shared below demonstrate some of SCA's stated commitments in action, several of which are tied to photographic records and the identification of racialized bodies, in keeping with the nature of our holdings and the (known) issues within them. The examples are not offered as exhaustive or definitive solutions to the identification of discriminatory records or as an unchangeable statement about how SCA will continue the work moving forward. They are offered instead as possible approaches for enacting equityand reconciliation-focused interventions in your own descriptive practice and

27 "File 65-1330: Waterloo Highschool Knitting Bee," University of Waterloo Archives Database, accessed November 17, 2020, https://archives.uwaterloo.ca/index.php/waterloo-highschool-knitting-bee. 
should not be taken as comments about how or where to start; each archivist will have to decide how to proceed based on the unique circumstances and uses of the records in their care. ${ }^{28}$

Remove and avoid the introduction of comments such as "never married" or "had no children" within biographical sketches unless these are relevant to the context of related records. The immediate reason for this guidance is rooted in equitable description as these types of caveats are rarely, if ever, noted when describing men but are common in overviews of the lives of women. This is also an attempt to reflect historical social realities and to make more transparent the systemic discrimination that women, particularly women of colour, have faced over time. Women, for example, were unable to get married if they wanted to have or keep careers. Women could not marry same-sex partners. Women could not marry if they found themselves, willingly or not, in caretaker roles, looking after war-wounded siblings or disease-stricken parents. Finally, women do not have to marry or have children to live meaningful, fulfilling, and well-rounded lives, yet archival descriptive practice has encoded suggestions that they do by needlessly commenting on what their lives lacked. ${ }^{29}$

Avoid unnecessary assumptions about gender or sex. As part of the itemlevel description I do prior to sharing digitized items online, I tend to prioritize the use of a person's name, when known, or to use unidentified person, when it is

For other overviews of equity- and reconciliation-focused archival work in action, see Jackie Dean, "Conscious Editing of Archival Description at UNC-Chapel Hill," Journal of the Society for North Carolina Archivists 16 (2019): 41-55, accessed November 10, 2020, http://www.ncarchivists.org/wp-content/uploads/2020/02/jsnca_vol16_dean .pdf; Grant Hurley, "Message from the Editor," Off the Record 36, no. 3 (2020): 3-4, accessed November 6, 2020 , https://drive.google.com/file/d/1ce6v8WaxwTJEG8dQjrg91Nlu7D1OHJmY/view; Melissa J. Nelson, "Archiving Hate: Racist Materials in Archives," Melissa J. Nelson (blog), March 18, 2020, http://melissajnelson.com/explore /information-management/archiving-hate-racist-materials-in-archives/; Armando Suárez, "Language Matters: Writing Inclusive Finding Aids," Archival Outlook (July/August 2020): 10-11, 20, accessed October 22, 2020, https:// mydigitalpublication.com/publication $/ ? m=30305 \varepsilon i=667849 \varepsilon p=12 \varepsilon v e r=h t m \mid 5$.

There are additional caveats to this type of biographical work that may apply to records in your care but fall beyond the scope of the vast majority of SCA records. For example, comments about whether a woman had children may be interpreted as a dismissal of the fact that an appalling number of often racialized women have undergone forced sterilization at the hands of systematically racist, colonial governments. It also ignores the reality that, for many, marriage has resulted in the loss of Indian status and qualification for disability benefits. See Miranda Bryant, "Allegations of Unwanted Ice Hysterectomies Recall Grim Time in US History," Guardian, September 21, 2020, https://www.theguardian.com/us-news/2020/sep/21/unwanted-hysterectomy-allegations-ice-georgia-immigration; Karen Stote, An Act of Genocide: Colonialism and the Sterilization of Aboriginal Women (Black Point, NS: Fernwood Publishing, 2015); Sarah Trick, "How the Ontario Disability Support Program makes falling in love a challenging proposition," TVO, August 24, 2018, https://www.tvo.org/article/how-the -ontario-disability-support-program-makes-falling-in-love-a-challenging-proposition. 
not, rather than defaulting to she or he. I also make every effort to use generalized statements such as "Members of [women's association name here]" rather than "Group of women." The decision to avoid unnecessary assumptions about gender or sex was intended to subvert any tendency to assume someone's gender based strictly on appearance. That said, this intervention requires case-by-case implementation rather than universal application due to its limitations. There are certain instances where indicating the presence of men or women, regardless of known affiliations or identifications, is essential to understanding the historical value of the records at hand. SCA's local history holdings include early photographic evidence of influential industrial companies such as Dare Foods, Dominion Rubber, Kaufman Shoes, and Schneiders. Knowing about the presence of (white) women in factory settings at the turn of the 2oth century or during periods of war is critical information for scholars studying historical labour relations, suffrage movements, and shifting family dynamics within Canadian society. Therefore, simply referring to a group of workers as "employees" without signalling the presence of men and women makes invisible records that are significant from a local and social history standpoint.

Prioritize family-inclusive language when and where appropriate. SCA staff have deemed this aspect of descriptive work important because, while it is easy to think of non-nuclear or non-traditional families as contemporary occurrences, they have always existed. A common example are families with children who were raised by their grandparents or other extended family members, perhaps because of previous pandemics, wars, or parental migration or incarceration. Another example are those children who have been adopted or fostered by caregivers for any number of reasons, including the ongoing removal of Indigenous children from their home communities. There are also countless among us who have found and cherished chosen families in the absence of biological familial entities due to forced separation, transphobia, homophobia, or other forms of discrimination and abuse people experience simply for existing. All these families, regardless of the reasons they have been brought together, deserve to have the circumstances in which they live respected and dignified. Being more inclusive with descriptive language, particularly at the item level, when images depicting unknown familial relationships are shared online is a way to make sure that happens. Basic examples of this practice in action include substituting adult or caregiver for (an assumed) 


\section{Parents' Information Bureau fonds}

\section{f $\square$ : in}

The Parents' Information Bureau (PIB) fonds consists of records from the clinic for family planning and birth control set up by A.R. (Alvin Ratz) Kaufman of the Kaufman Rubber Company in the 1930s. The main branch of the PIB was located at 410 King Street West in Kitchener, Ontario. Between the mid-1930s and the mid-1970s the PIB published a series of numbered reports, forms, and informational pamphlets regarding birth control and sterilization. The publication numbers were reused by the PIB for revised editions and for documents containing information about related topics that were likely circulated as part of an information packet.

\section{Content note: The views expressed in PIB publications reflect the era in which they were produced. They include family planning thinking rooted in eugenics, the belief that the genetic makeup of the human population can be improved by limiting the ability of people deemed inferior from reproducing. Demeaning language about lower class and disabled people appear throughout. Information about the handling of this type of language in archival descriptions can be found on the Special Collections \& Archives website.}

\begin{tabular}{|l|l|l|l|l|l|l|l|l|l|l|l|}
\hline & Grid view List view \\
\hline
\end{tabular}

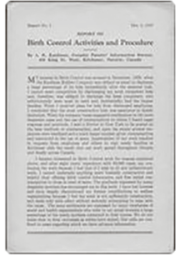

\#01: Report on Birth Control Activities and Procedure

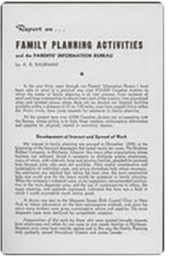

\#01: Report on family planning activities and the Parents' Information Bureau

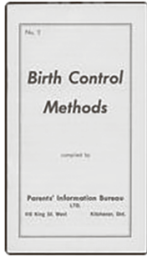

\#02: Birth control methods

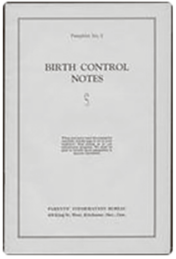

\#02: Birth control notes

FIGURE 2 Screenshot of the overview and content note for the Parents' Information Bureau fonds in the Waterloo Digital Library. Source: "Parents' Information Bureau fonds," University of Waterloo Digital Library, accessed October 24, 2020, https://digital.library.uwaterloo.ca /uwdl-ge449512-8478-4513-8ood-fi716egbcd27/parents-information-bureau-fonds?display=grid.

parent - and baby, infant, or child in place of son or daughter. ${ }^{30}$

Add and expand existing fonds- or collection-level content warnings. Figure 2 is a screenshot from a collection included in the Waterloo Digital Library. It contains highly used and requested records from the Parents' Information Bureau (PIB), a Kitchener organization created in the 1930s to promote and distribute birth control. The PIB and the thinking behind its operations and services were heavily informed by eugenics, specifically, the belief that the human population could be improved by limiting the reproduction of "inferior" people.

30 For other considerations, see Margaret Middleton, "Family Inclusion," margaretmiddleton, accessed October 29, 2020, https://www.margaretmiddleton.com/family-inclusion. 
To more immediately identify the records within the PIB as potentially harmful, traumatic, or otherwise offensive, a content note was added to the fonds-level records in both the Waterloo Digital Library and the Archives Database. It reads, "The views expressed in PIB publications reflect the era in which they were produced. They include family planning thinking rooted in eugenics, the belief that the genetic makeup of the human population can be improved by limiting the ability of people deemed inferior from reproducing. Demeaning language about lower class and disabled people appear throughout." The note is by no means a perfect solution, and similar warnings do not appear in each of the item-level records where dehumanizing language appears,${ }^{31}$ but this type of fonds-level note is an improvement over the note that was previously associated with this collection: "The views expressed here don't reflect those of UWaterloo."

Facilitate improved access to records related to Indigenous communities. Although much of SCA staff's attention has been directed at revising and avoiding the introduction of problematic language in descriptive records, initial attempts have also been made to better identify records pertaining to First Nations, Métis, and Inuit in Canada. Since we hold very few fonds or collections directly related to or created by these groups, we are paying particular attention to instances where it is not otherwise apparent that information related to Indigenous peoples is included within a larger set of records. One example of this practice was established when historical maps in our holdings were catalogued and digitized for improved access.

The map in figure 3 documents the districts in Rainy River and Thunder Bay, which is the aspect of aboutness that would normally be prioritized in the corresponding catalogue record. The map, however, also includes a series of greyshaded areas that are not included in the legend but are marked with the initials $I R$, indicating the location of Indian reservations. Following consultation with various colleagues, ${ }^{32}$ "Indigenous peoples - land tenure" was added to maps where information about Indigenous land was included but was not the focus or purpose of the map.

While some may argue that this type of intervention goes against traditional cataloguing practice, from a reconciliation and archival descriptive standpoint, SCA staff have the authority and ability to add the access points deemed most

31 This type of case-by-case inclusion has been deemed unsustainable based on staff and resourcing capacity.

32 Thanks to Jordan Hale, Antonio Muñoz Gómez, and Maria Reinhard for their input and assistance. 


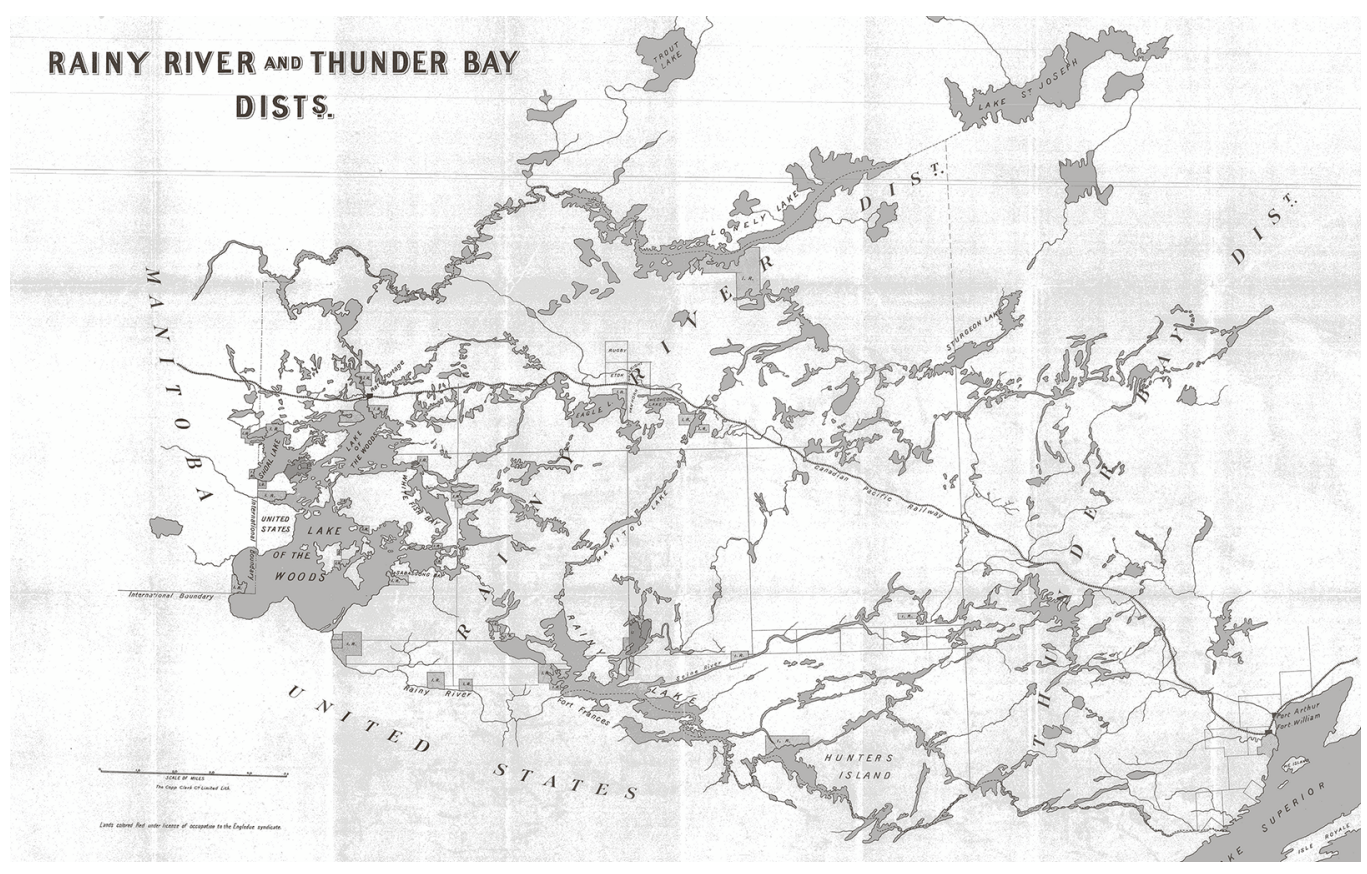

FIGURE 3 Map depicting districts in Rainy River and Thunder Bay that includes great areas marked with IR to denote Indian reservations. Source: University of Waterloo Library, Special Collections \& Archives, G24493, Rainy River and Thunder Bay Dist., n.d.

appropriate for end-users. For example, while the residential school system is often the entry point for people's thinking about reconciliation, colonialism and the cordoning off of land for colonial settlement versus Indigenous livelihood is a key part of understanding the thinking behind the school system. Surfacing related information is a way to highlight that relationship. Including land tenure authorities is also a way to help surface information that can be referred to and used as part of land claim processes across the country. ${ }^{33}$

33 Land tenure authority work, where the topic is not the focus of an item, is currently happening only within SCA. Discussions have been initiated with colleagues in the cataloguing department to expand the scope of the work to collections outside of SCA. It is unclear how or if this type of land-related intervention will be expanded to finding aids; the nature of our holdings, thematic areas, and past collecting policies means there are few, if any (public) examples of how to better describe and highlight records related to Indigenous peoples, treaties, or land. 
This type of authority work has been expanded to include the intentional use and introduction of more precise descriptive language pertaining to Indigenous peoples in Canada. The effort has been made to facilitate keyword searching based on current, culturally precise language as a means of addressing the gap in our holdings related to Indigenous peoples and themes. The finding aids for records in the E. Palmer Patterson Fonds are one such example. ${ }^{34}$ They were recently redescribed by archivist Nicole Marcogliese to refer to First Nations and Inuit using current and appropriate language. The work included documenting the changes both in the names used over time to refer to peoples, such as the Nisga'a or Tlingit, and in the corresponding authority records that document and make transparent the relationship between colonialism and Indigenous culture(s) over time. ${ }^{35}$

\section{Challenges and Work Ahead}

Several challenges have arisen since SCA staff began working to integrate equity- and reconciliation-focused thinking into existing efforts to improve online access to our holdings.

From a practical descriptive standpoint, we have struggled with consistently and reliably documenting known issues, given that there are no RAD fields expressly dedicated to content warnings or to the documentation of descriptive interventions undertaken by archivists to address problematic content. Although the standard grants archivists the freedom to describe records in a manner that aligns with the mandate of the institution, the needs of researchers, and the environment in which the records will be used, there are no guidelines about how to handle blatantly racist, sexist, ableist, transphobic, or otherwise offensive and dehumanizing language or imagery, nor is there any guidance about where this should be tracked. ${ }^{36}$ The absence of guidance about these

\footnotetext{
34 "Fonds SCA129-GA102: E. Palmer Patterson fonds," University of Waterloo Archives Database, accessed November 17, 2020, https://archives.uwaterloo.ca/index.php/e-palmer-patterson-fonds-2.

35 For documented examples of name changes and variations within Canada, see "First Nations, Métis, Inuit Indigenous Ontology," National Indigenous Knowledge and Language Alliance, accessed February 5, 2021, https://docs.google.com/spreadsheets/d/e/2PACX-1vSOKcm9HB -28iSqNN3sQd5hV7bMLMGpCeGLOdkQgyg2AiZAMWUF0sp98GyxIvLXYIWqSZ3nX_j_q4UN/pubhtml.
}

36 Note, for example, that keyword searches for race, racist, or racism in the Rules for Archival Description, last 
issues is both a strength and a weakness of the standard. Archivists are given guidance that allows us to make descriptive decisions that best suit the environment where we work and the needs of the researchers we serve, which is clearly positive. Conversely, those unfamiliar with the body of literature challenging the neutrality of archives might progress through their careers guided by standards that never prompted them to consider the harm caused by unacknowledged instances of discrimination in archival records.

The lack of acknowledgement or direction regarding pressing social issues such as systemic racism, transphobia, and ableism by descriptive standards like $R A D$ presents a serious challenge for archival practitioners who rely on these guidelines to undertake their day-to-day work. Although newly released and thoughtfully drafted documents such as A Reconciliation Framework for Canadian Archives provide guidance on fundamental aspects of archival practice such as arrangement and description, the failure of the governing bodies responsible for maintaining descriptive standards to update these in response to contemporary social issues directly impacts the profession's ability to enact that guidance reliably or consistently. Some will rightly question the feasibility of updating descriptive standards in response to every major social development - a point of concern I agree with - yet there is undoubtedly middle ground to be found. That $R A D$ was last updated in 2008 firmly presents an opportunity for the introduction of basic improvements that would significantly impact how well equity and reconciliation frameworks are embedded into the descriptive process and how effectively the defining social moments of the past several decades are captured and documented. ${ }^{37}$

SCA staff have attempted to navigate RAD's absence of guidance on problematic content and related interventions by using the general note field to flag known issues. ${ }^{38}$ The approach works best if one ignores one result of doing

revised in 2008, yield zero hits. The same is true for keyword searches for sexism, ableism, transphobia, and variations of these terms.

The Canadian Council of Archives undertook the groundwork for a RAD revision in 2015 in the form of a survey, administered with assistance from provincial and territorial associations, requesting feedback about improvements to the standard. The outcome of the survey and plans for future improvements have yet to be shared publicly.

RAD direction for the general note field: "1.8B21. General note. Use this note to record any other descriptive information considered important but not falling within the definitions of the other notes." Canadian Committee on Archival Description, Rules for Archival Description, 1-69. 
so: critical information being lumped in with other content in what is effectively RAD's "kitchen sink." 39 It also creates a risk that researchers may miss the information altogether. RAD could facilitate the documentation of equity and reconciliation interventions by introducing a field dedicated to tracking them. At the same time, a field dedicated to records related to or created by Indigenous peoples has the potential to dramatically improve the implementation of descriptive guidelines rooted in reconciliation and in upholding the Indigenous rights presented in the Truth and Reconciliation Commission and the Royal Commission on Aboriginal Peoples and in the United Nations Declaration on the Rights of Indigenous Peoples, among other documents. ${ }^{40}$ As Krista McCracken astutely noted in 2019, "Some members of the archival profession have demonstrated a reluctance to critically engage with the colonial practices that continue to marginalize Indigenous peoples within the archival record and have failed to address the continued barriers many face in even accessing the archives." 41 Prompting archivists to consider the implications of colonialism as part of the archival descriptive practice would definitively underscore, for example, the responsibility of all Canadian archivists to participate in the reconciliation process. Additional descriptive fields cannot and will not put an end to the longterm, deeply engrained colonial implications of traditional archival description, but they can, at a minimum, standardize how and where actions to disrupt these are documented, searched for, and built on over time. ${ }^{42}$

Beyond the practical challenges of evolving descriptive practice within the boundaries of existing descriptive standards, several issues tied to the over-

39 For another example of this type of challenge, see Dominique Foisy-Geoffroy, "Between Duty to Remember and Imperatives of Reconciliation: Procedures for Writing Culturally Sensitive Titles for Descriptions of Indigenous Materials at Library and Archives Canada" (presentation at the 2019 Canadian Research Knowledge Network Access to Knowledge Conference, Ottawa, October 18, 2019), https://www.crkn-rcdr.ca/sites/crkn/files/2019-11 /Decolonizing-Metadata_6c_LAC_DFG_EN.pdf.

40 For a thorough and essential overview of the intersection between colonial frameworks and Canadian archival practice, see Krista McCracken, "Challenging Colonial Spaces: Reconciliation and Decolonizing Work in Canadian Archives," The Canadian Historical Review 100, no. 2 (2019): 182-201.

41 McCracken, "Challenging Colonial Spaces," 183.

42 There are also implications regarding data migration at play with the introduction of new and dedicated fields related to equity and reconciliation. Capturing critical information along with inconsequential or non-essential administrative information in a general notes field means that valuable documentation about descriptive remediation is at risk of being collapsed or completely overlooked as part of future descriptive clean-up and migration efforts. 
whelming homogeneity of the (Canadian) archival profession have arisen. Earlier, I shared that there are currently six full-time staff members working in SCA. It is important to underscore now a fact I neglected to include above: that we, like most of our colleagues at the UWaterloo Library, are able-bodied and white or white-passing. Although we were born and raised in different locations, we are products of a Western education system. Despite varied post-secondary educational pursuits and professional development efforts, we bring a homogeneous set of foundational educational backgrounds to our archival practice. That is not to say that we have not dealt with discrimination or bias as individuals or that we do not have a diversity of experiences to pull from while describing and working with records. However, it does mean the following: we likely have not been profiled because of the colour of our skin; we likely have not struggled with learning a new language in a new country; we likely are not assumed to be (un)able to accomplish something based on our appearance; we likely find it challenging to imagine not having our cultures and beliefs both prioritized and championed in social, educational, and archival settings.

As a result, there are things we simply do not know and may never know, and this is something we must constantly navigate in our day-to-day work. This is a known challenge in the field. Jessica Tai has called for the normalization of not knowing as a means of critical self-reflection, rooted in cultural humility that "prompts archivists to acknowledge that they will never have all the answers, therefore opening space for other voices, and allowing non-traditional forms of expertise to inform decision making." ${ }^{33}$ Sam Winn has similarly examined the archivist's capacity to ever truly know something, arguing that "any ambitions we have of handling the historic record with fairness or equity must be shored up by continual self-examination, humility, and scholarly engagement." ${ }^{34}$ In the case of SCA staff, responding to these prompts means assuming that students, staff, faculty, and off-campus community members from cultural, social, and economic backgrounds other than our own are equally equipped to guide and contribute to the (re)description of our records. It means giving co-op students the authority to take ownership of descriptive work that would not be possible

\footnotetext{
43 Jessica Tai, "Cultural Humility as a Framework for Anti-Oppressive Archival Description," Journal of Critical Library and Information Studies 3, published ahead of print, October 1, 2020, 3, https://journals.litwinbooks.com /index.php/jclis/article/view/120/75.

44 Winn, "The Hubris of Neutrality in Archives."
} 
without their cultural knowledge and giving them credit for both their labour and their expertise. ${ }^{45}$ It means knowing when we need help and stepping aside to make space for it.

A simple but illustrative example involves the use and presence of acronyms in descriptive records. Although SCA staff make a point of spelling these out the first time they are used, the hierarchical nature of descriptive records means explanatory notes may get missed. At the same time, certain acronyms are so familiar they can be overlooked. Working with students from a variety of cultural backgrounds as part of class-based instruction has continued to underscore unanticipated disconnects by highlighting the myriad ways people search for and read about collections that are not necessarily front of mind when (re)descriptive work is undertaken. When I see $C B C$, for example, I most readily think of the Canadian Broadcasting Corporation. People of Chinese heritage, however, may be more inclined to default to Canadian-born Chinese. ${ }^{46}$ Another example is a set of records, held as part of the Breithaupt Hewetson Clark Collection, regarding Taber Hill, a Wyandot (Huron) burial mound in Toronto, Ontario. The records include photographs of Indigenous elders and community members participating in a ceremony on the land. Recognizing our collective inability to understand and respectfully describe what is captured in the images, my colleague Nicole Marcogliese welcomed former UWaterloo co-op student Katie Turriff's interest in the records. Drawing on a renewed relationship and exploration of her Mohawk ancestry, she researched and developed an overview of the ceremony, the people participating in it, and the importance of the land, which went above and beyond anything SCA staff could have established without her contribution.

Finally, something we have only started to grapple with is how to talk more openly about the inherent whiteness of our collections and the way they embody Canada's ongoing history of settler colonialism. In their review of Canadian archives, Crystal Fraser and Zoe Todd noted that "the majority of archival documents in Canadian archives have been produced by non-Indigenous people: namely white men who dominated exploration, political and other 'great

\footnotetext{
45 Financial compensation is an essential aspect of inviting others into the archival description practice by way of consultation or hands-on work. Mention of it has been omitted here since co-op students working with the department are paid staff members.

46 This example was raised with SCA staff by Jessica Blackwell, Librarian, Special Collections \& Archives, while she was working with undergraduate students using primary resources as part of a course assignment.
} 
men' tropes of Canadian history." 47 Krista McCracken echoes Fraser and Todd, explaining that "Canada's past has been largely narrated by settlers, viewing the world through a colonial lens and describing Indigenous communities using a non-Indigenous worldview."48 The primacy of white men is equally prevalent in the United States, where Alexis A. Antracoli and Katy Rawdon explained in their review of name authorities in archival collections that it has "traditionally been white men whose papers have been collected, who have been at the head of organizations whose records have been preserved, and who have had the means and the sense of self-importance to create records." 49 While critically examining a pattern of white reverence in biographical sketches, Jarrett Drake noted that "These practices and this language are remnants of a colonized mode of thinking about the world through the gaze of great white men, whose complexities and contradictions previously could only be explored in the archives by similarly complicated and great white men." 50

The legacy and ongoing prevalence of colonial thinking is very much present in several of SCA's major holdings. The extensive local history collections closely mirror the white, German history of the region, which has created a descriptive framework and a legacy of implied and assumed whiteness. That whiteness extends to several of the thematic collecting areas established since the department opened, including the collections mentioned earlier, which were donated in the mid-196os as part of a donation by the National Council of Women of Canada (NCWC). The NCWC membership was dominated by middle-class white women who shaped the purview and concerns of the organization, and their records now act as the backbone of SCA's current offerings in the area of women's studies.

Although there is consistent demand for primary resources related to the experiences of Black, Indigenous and people of colour (BIPOC) communities, SCA staff regularly struggle to locate relevant records using existing (legacy) descriptive records because most of our fonds and collections reflect white local

\footnotetext{
47 Crystal Fraser and Zoe Todd, "Decolonial Sensibilities: Indigenous Research and Engaging with Archives in Contemporary Colonial Canada," in Decolonising Archives (n.p.: L'Internationale Books, 2016).

48 McCracken, "Challenging Colonial Spaces," 186.

49 Alexis A. Antracoli and Katy Rawdon, "What's in a Name? Archives for Black Lives in Philadelphia and the Impact of Names and Name Authorities in Archival Description," in Ethical Questions in Name Authority Control, ed. J. Sandberg (Sacramento, CA: Library Juice Press, 2019) 307-36.

50 Drake, "RadTech Meets RadArch."
} 


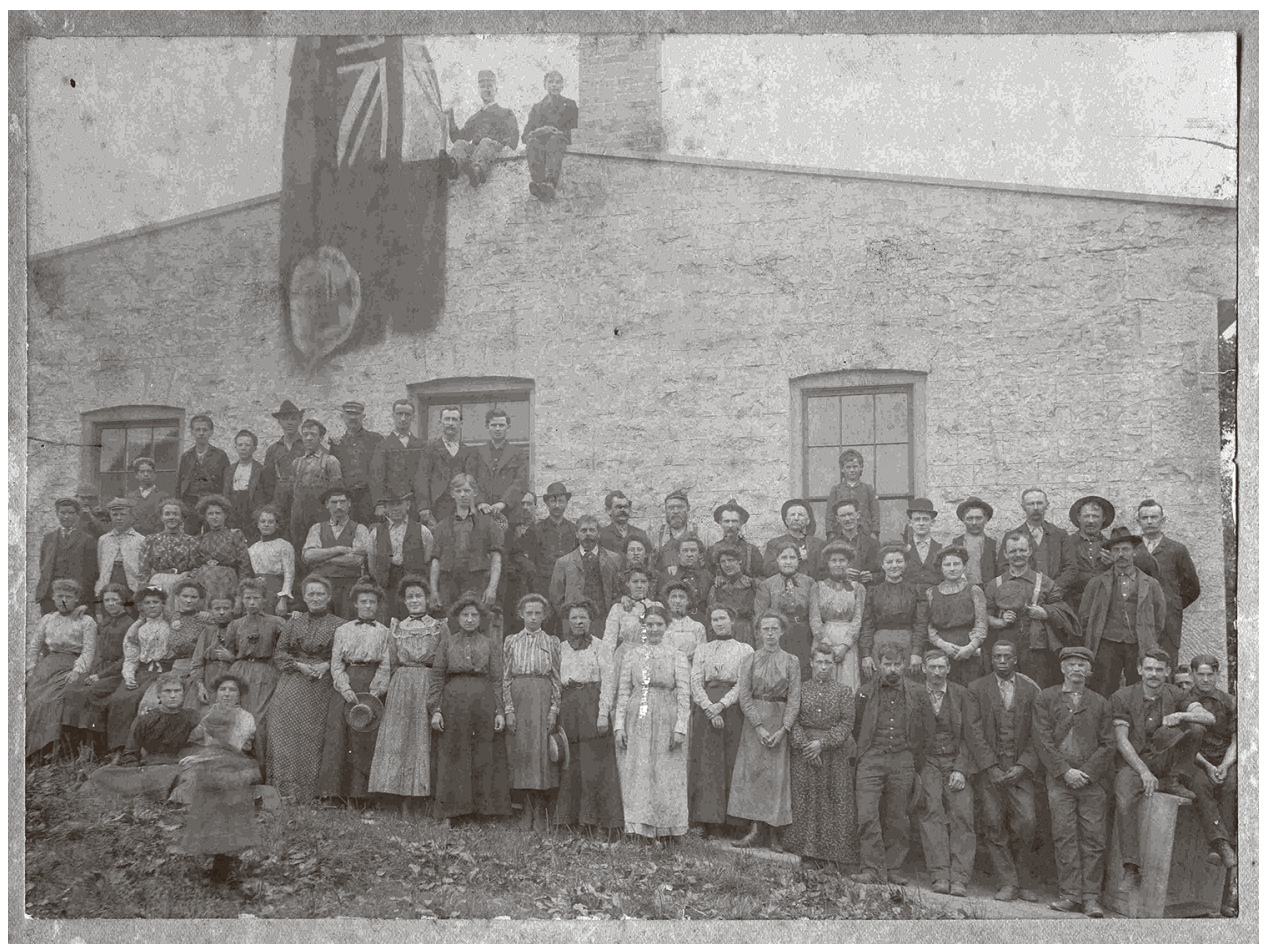

FIGURE 4 Mounted group portrait of employees of the George Pattinson Woollen Mill casually posed in several rows outside of a stone building. Two employees are sitting on top of the building with a flag, and a blurry child is visible walking through the frame at bottom left. Source: University of Waterloo Library, Special Collections \& Archives, George Pattinson Woollen Mill fonds, GA227-3-17, Woollen Mill employees [ca. 19oo].

history. This reality has presented an uncomfortable truth: identifying records about equity-seeking and racialized peoples within SCA holdings renders people notable for not having white skin. Because most of the department's archival holdings represent white people and white organizations, the corresponding descriptive records were written and continue to exist in a realm where colour is effectively ignored because whiteness is the assumed default. Why, for example, would an archivist have indicated that an individual or a group of people in a photograph were white if everyone in the photograph was white?51

51 For an early and instructive assessment of the shortcomings of a uniform omission of race, see b. binaohan, 
Figure 4 shows a photograph of woollen mill employees from what is likely the turn of the 2oth century. Indicating that there is a Black person, whose name is unknown, in the front row, a few people from the right, would be an efficient way to flag the presence of a non-white employee, but doing so instantly others this person as notable simply because they are Black. Their presence, however, is historically significant given how uncommon it was for the lives of Black people living and working in the Region of Waterloo during this period to have been documented. And this point is crucial: it is not that it was uncommon for Black people to have lived and worked in the region, but it is instead uncommon for their lives to have been documented and for related records to have been maintained by institutions like my own. ${ }^{52}$

We do not yet have an answer for how to address this issue, and we have only just begun internally discussing how to proceed. One possible approach may be to create a new thematic area tag to pull together records in SCA holdings reflecting, pertaining to, and capturing the lives of non-white people. A tag at the fonds or collection level would immediately signal to researchers that information about equity-seeking communities, for example, is present within a particular set of records. These pointers would eliminate the need to rely on keywords alone to indicate the presence of records related to BIPOC groups or individuals and would leave it up to the researcher seeking the records to determine whether they were in or out of scope. ${ }^{53}$ Another way forward may be to mirror the identification of BIPOC-related records in our holdings with the identification of records related to white people, and by extension whiteness, in those same holdings. Doing so efficiently at the file and item level is beyond the scope of what SCA can currently accomplish, but Armando Suárez's review of the actions being undertaken by Princeton's archival description and processing team points to an

\footnotetext{
"What Matters for Archival Image Description?," i dream of being possible (blog), June 27, 2014, https://biyuti .com/satifice/what-matters-for-archival-image-description/.

53 For more on the limitations of keyword searching when seeking records containing racist content, see Nelson, "Archiving Hate: Racist Materials in Archives" and Melissa Nelson, "Archiving Hate: Legacy Descriptions and Offensive Materials in Archives" (presentation to Institutional Development Committee Members' Symposium, Archives Association of Ontario, October 22, 2020), https://docs.google.com/presentation/d /12ajiFTXfpz3vOvXJOHtll9yzVNh6uFEKPD9DR79hcQ0/edit\#slide=id.g35f391192_00.
} 
initial way forward. ${ }^{54}$ As part of the team's work, information about the perspective of the record creator(s) is being added to fonds and collection overviews. For example, the notation "largely from the perspective of settlers" is used to contextualize the Western Americana Miscellaneous Manuscripts, indicating up front the type of narrative and social position that frames the corresponding records. A similar approach could be reasonably introduced to SCA's fonds- and collection-level overviews of local history holdings, which often already include a note about a family's ancestry. Indicating that the family is also white and of a particular social and economic class would better contextualize both the nature of their lives and the records with which they are associated.

From a theoretical standpoint, Antonina Lewis' notion of archival fragility offers additional guidance by putting a name to what is signalled by not acknowledging or acting to address the codified distinctions between "white" and "not white" in the archives. As Lewis explains, "Archival fragility subsumes the realities of people who experience records as barbs, barriers, and weapons under a professionally normalized construct of the greater historical good of the archival mission." 55 Put another way, by choosing a hubris rooted in the sanctity of archival neutrality over a humility rooted in the relinquishment of power and a destabilization of the way things have always been done, the archivist becomes complicit in perpetuating harm. As an example of archival fragility, Lewis points to concerns about the long-term preservation of repatriated records, whereby misdirection about record safety is used to safeguard archival power. I propose that this type of concealed evasion may be equally at play when the identification and remediation of overt whiteness in legacy finding aids is framed as an impossible undertaking requiring too much work. By focusing on comfortably familiar neoliberal deflections like time and resources, archival fragility side-steps meaningful, action-oriented change. This rejection of accountability can also be understood as a manifestation of what Eve Tuck and K. Wayne Yang call settler moves to innocence, specifically "those strategies or positionings that attempt to relieve the settler of feelings of guilt or responsibility without giving up land or power or privilege, without having to change much at all." ${ }^{56}$ Combined, archival fragility

\footnotetext{
54 Suárez, "Language Matters."

55 Antonina Lewis, "Omelettes in the Stack: Archival Fragility and the Aforeafter," Archivaria 86 (Fall 2018 ): 52.

56 Eve Tuck and K. Wayne Yang, "Decolonization Is Not a Metaphor," Decolonization: Indigeneity, Education and Society 1, no. 1 (2012): 1-40.
} 
and settler moves to innocence can be used to interrogate and call into question the prevalence within academia of equity, diversity, inclusion, and reconciliation statements that fail to yield meaningful and sustained change. For those unwilling to cede power or engage with difficult truths about (contemporary) archival practice, these types of statements become a refuge from the difficult work of enacting change rather than mechanisms through which equity and reconciliation work can be enacted in and through day-to-day archival practice.

In terms of further work, it is the extent of what must be (un)done that presents one of the biggest challenges. While SCA staff have begun identifying problematic content and intentionally improving the findability of records reflecting marginalized peoples and pasts, the effort is not a dedicated or sustainably resourced endeavour. It is work that, for logistics and efficiency's sake, has been and will continue to be integrated into the ongoing review of records as part of database migration and a push to share more of the department's digitized holdings online. Although we collectively understand the work to be ongoing and long term, we lack a plan for ensuring that it does in fact continue or a method for measuring success beyond pointing to record updates and newly created content warnings. Discussions about ensuring the future sustainability of the work or about the potential ramifications of a significant change in department staff or library administration have yet to take place. Where we have made headway, however, is in formalizing and documenting equity and reconciliation work in governing department policies and workflows; we have also begun the process of updating donor agreements to make clear the department's commitment to these values. Doing so ensures that the motivating principles are woven into the entirety of the department's operations, minimizing the potential for wholesale dismissal or redirection of the work moving forward.

\section{Conclusion}

While there is no easy or universally applicable way to integrate equity- and reconciliation-informed thinking into archival practice, starting the process requires acknowledging the shortfalls of the descriptive records in our care and identifying grounds for intervention that best align with the mandate of our organizations, the people using the records, and the histories of those people and places we are tasked with documenting. Often this means taking a critical look 
at how the diversity of our personal experiences and professional environments, or lack thereof, impacts our practice. There have been long-standing discussions in archival literature about the need for descriptive interventions, but contributions by Canadian practitioners have been notably absent. This article is an attempt to call in and make space for those members of the archival profession who are attempting to bridge broader theoretical and professional discussions with their day-to-day practice. There is no single right way to do equity and reconciliation work, and the time to start implementing change is always now. It is hoped that talking openly about the context and thinking behind changes to SCA's approach to language in archival descriptions will prompt other practitioners to reflect on areas for improvement within their own practice to make the seemingly insurmountable incrementally achievable.

BIOGRAPHY Danielle Robichaud (she/her) is a white settler Canadian who lives and works in Waterloo, Ontario, on the Haldimand Tract as a digital archivist in Special Collections \& Archives at the University of Waterloo Library. She holds an MLIS from the University of Western Ontario and an MA (sociology) from Queen's University. Her career began in the public service, where she worked in enterprise information management at Natural Resources Canada and as a reference librarian at Transport Canada before managing various digital and descriptive projects at the Henri J.M. Nouwen Archives and Research Collection in Toronto, Ontario. In her current role, Danielle is responsible for the creation, management, and use of digitized primary resources as well as for improving the online discoverability of archival holdings. She was a founding member of the Association of Canadian Archivists' Equity Task Force and has served as a board director for the Archives Association of Ontario (AAO). In 2018, she was awarded the James J. Talman Award by the AAO for her work related to Wikipedia and the implementation of the Truth and Reconciliation Commission of Canada's Calls to Action. 